Florida International University FIU Digital Commons

FIU Electronic Theses and Dissertations

University Graduate School

$7-25-2005$

\title{
Do developmental assessments impact parental stress?
}

Ivy Campos

Florida International University

DOI: $10.25148 /$ etd.FI14052553

Follow this and additional works at: https://digitalcommons.fiu.edu/etd

Part of the Psychology Commons

\section{Recommended Citation}

Campos, Ivy, "Do developmental assessments impact parental stress?" (2005). FIU Electronic Theses and Dissertations. 1989. https://digitalcommons.fiu.edu/etd/1989

This work is brought to you for free and open access by the University Graduate School at FIU Digital Commons. It has been accepted for inclusion in FIU Electronic Theses and Dissertations by an authorized administrator of FIU Digital Commons. For more information, please contact dcc@fiu.edu. 
Miami, Florida

A thesis submitted in partial fulfillment of the requirements for the degree of MASTER OF SCIENCE in PSYCHOLOGY by Ivy Campos 
To: Interim Dean Mark Szuchman

College of Arts and Sciences

This thesis, written by Ivy Campos, and entitled Do Developmental Assessments Impact Parental Stress?, having been approved in respect to style and intellectual content, is referred to you for judgment.

We have read this thesis and recommend that it be approved.

William Kurtines

Jacob Gewirtz

$\overline{\text { Marilyn Montgomery, Major Professor }}$

Date of Defense: July 27, 2005

The thesis of Ivy Campos is approved.

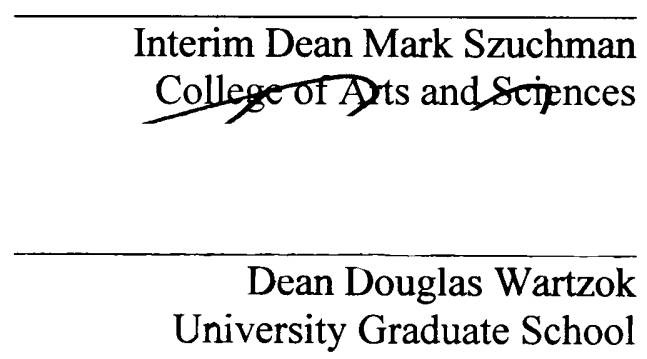

Florida International University, 2005 


\section{DEDICATION}

I dedicate this thesis to my partner Dr. Mike de Cardenas for providing me with the love, support, and understanding needed in order to achieve all of my dreams. 


\section{ACKNOWLEDGMENTS}

First I would like to acknowledge the support and supervision of my committee chair and advisor, Dr. Marilyn J. Montgomery. Thank you for all your patience and support, and for providing me with the space to continuously grow as a professional. I would also like to thank my thesis committee members, Drs. William Kurtines and Jacob Gewirtz for sharing their knowledge and providing me with guidance throughout this process.

To my friends and peers at the Youth and Family Development Program at FIU, I would like to express my appreciation for your continuous support, encouragement, and above all assistance throughout this process: Jessica Bryson, Sharon Hollander, and Melody Whiddon. Without your dedication and hard work this thesis would not have been possible.

To my friends Millie Cordaro, Lynn Hernandez, Michelle Hospital, and Christina Lalama; I want to thank you all for the encouragement and support you provided for me. But above all, you helped me keep my sanity throughout this process. I would also like to thank my family for their love and patience, of which I could never fully express in words alone.

Finally, I would like to take a moment to thank Dr. Jose Vargas, for his support and encouragement throughout this entire process. Without the patience and love of everyone, this thesis would not have been possible. 


\title{
ABSTRACT OF THE THESIS
}

\section{DO DEVELOPMENTAL ASSESSMENTS IMPACT PARENTAL STRESS?}

\author{
by
}

\author{
Ivy Campos
}

Florida International University, 2005

Miami, Florida

Professor Marilyn Montgomery, Major Professor

This study is a preliminary exploration of whether parental stress can be influenced by receiving the developmental assessment information about a target child. The study consisted of 25 self-referred families who sought developmental assessments from the Youth and Family Development Program (YFDP) at Florida International University, with children between 4 to 12 years of age. All parents contacting YFDP for developmental assessments completed a pre-test (Parenting Stress Index-Short Form (PSI-SF) over the telephone. Participants (both parent and child) completed an assessment battery during Weeks 1 and 2, and a final feedback session (Week 4) was provided for the parent on the results of these assessments. The participants were contacted four weeks (Week 8) after the feedback session to complete the post test (PSISF). Results of the pre and post-test were compared. As expected, parents' stress was significantly lower at one month following the developmental assessment intervention compared to stress at intake, across domains of parent distress, difficult child, parentchild dysfunction, and total parenting distress. Implications for using developmental assessments in parent interventions are discussed. 
I. INTRODUCTION

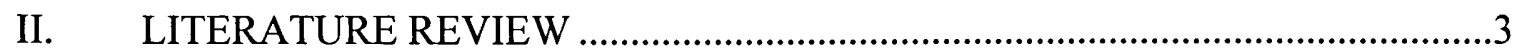

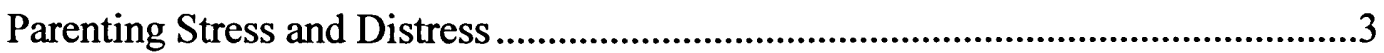

Child Problems and Parenting Stress ........................................................................

Parent/Child Dysfunction and Parenting Stress ..................................................6

Developmental Assessments and Parenting Stress ..................................................8

Research on Parental Stress using the Parenting Stress Inventory ..............................9

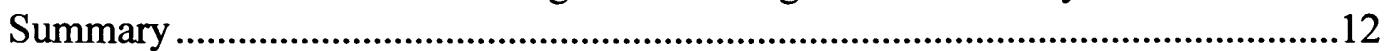

Research Hypothesis ..............................................................................................13

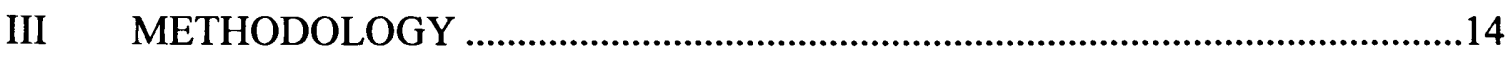

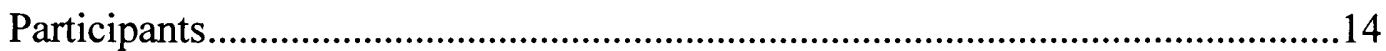

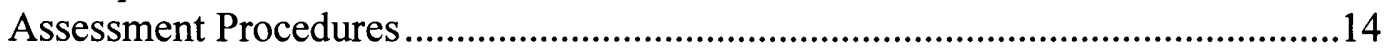

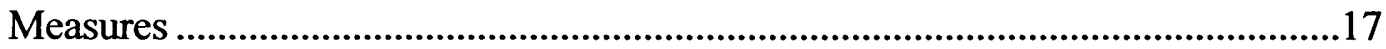

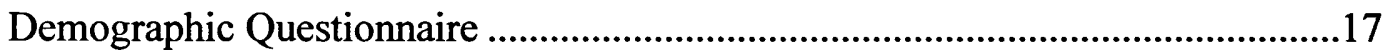

The Parenting Stress Index .....................................................................................

The Parenting Stress Index-Short Form................................................................18

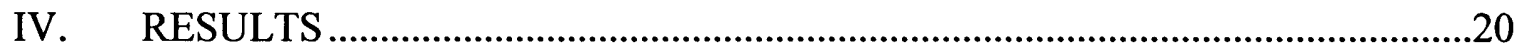

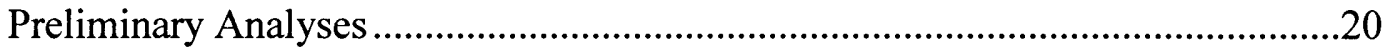

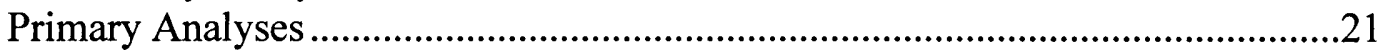

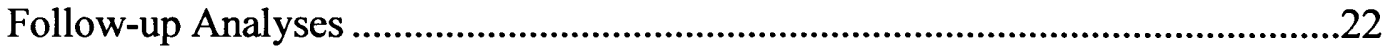

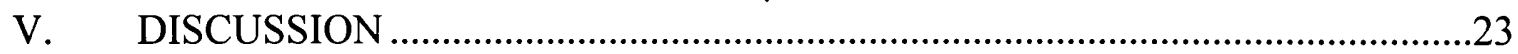

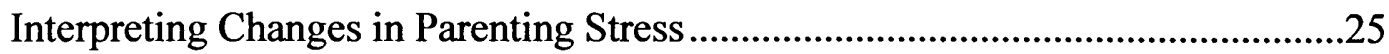

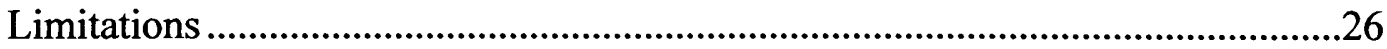

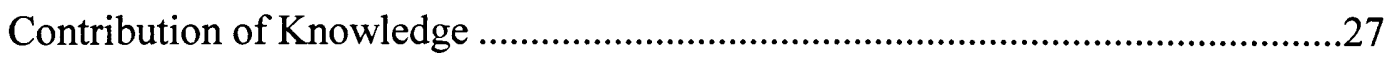

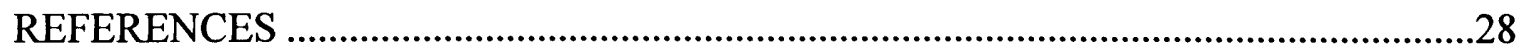

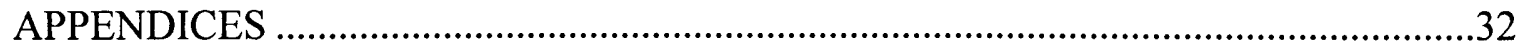




\section{CHAPTER I}

\section{INTRODUCTION}

The assessment of children has many purposes, three of which are particularly pertinent to mental health counselors: (a) to evaluate child learning and development, (b) to identify children in need of special services, and (c) to diagnose problems so that appropriate treatment can be implemented (Shepard, Kagan, \& Wurtz, 1998). Parents are typically involved in the child assessment process, service providers such as pediatricians and educators believe that information is best gathered from those who have the most direct contact with the child, since the child is unable to provide all the necessary information (Gestwicki, 2000).

In many instances, the assessment must be completed before intervention can begin. While the typical goal of a child assessment is to provide an expert with information about a child, many professionals believe that a well-done assessment is itself a helpful "intervention," whether or not it marks the beginning of a longer treatment program (Simpson, Korolof, Friesen, \& Gac, 1999). Child health specialists advocate using assessment opportunities in clinical settings to provide anticipatory guidance by giving parents information about what they can do to enhance their children's growth,

development, and functioning (Nelson, Wissow, \& Cheng, 2003). Indeed, many parents report that they learn new ideas, feel a sense of relief, and realize that they are not alone with their questions after they discuss their child's development with a professional (National Center for Infants, Toddlers, \& Families, 1997).

Despite these views, the impact of providing parents with child assessment feedback has received relatively little attention in the clinical literature. Virtually no 
studies have empirically assessed the claim that involving parents in a developmental assessment, which provides them feedback, can reduce parent stress and give them a sense of relief with respect to concerns about their child's problems. Therefore, the primary purpose of this study was to examine whether or not parents' stress (as measured by the Parent Stress Inventory scales of Parental Distress, Difficult Child, and ParentChild Dysfunctional Interaction) was reduced after receiving developmental feedback about their child.

The study is significant for several reasons. First, it explores the potential utility of child developmental assessments to reduce a parent's distress, negative perceptions of their child, and dysfunctional interactions with their child. As such, it is consistent with a Stage I-type study as characterized by the three-stage model of intervention research used in behavioral treatment research at the National Institute of Health (NIDA, n.d.). Stage I involves the development and pilot-testing of interventions based upon or translated from basic behavioral, cognitive, or clinical science and theory. Because parents are increasingly regarded as integral to effective systems of care for children, this study serves an important function as a pilot study for future research, which can assess the intervention with a Stage II clinical trial in which the use of a control group will permit stronger conclusions about the impact of developmental assessments. Nevertheless, this study offers preliminary support for using developmental assessments as a component of child/family therapy. Specifically, results from this study support the inclusion of development of assessments as a promising component of parent/child prevention and intervention programs. 


\section{CHAPTER II}

\section{LITERATURE REVIEW}

The primary purpose of this study was to investigate whether developmental assessments and feedback impact parental stress. Being a parent is often stressful for many parents, and ameliorating parenting stress is important because it has been shown to impact both the child's developmental process and overall family cohesion (Carr, Dunlap, Horner, Koegel, Turnbull, Sailor, Anderson, Albin, Koegel, \& Fox, 2002). Studies have shown that with the appropriate tools, parenting can be a more positive experience for all those involved.

The following literature review outlines relevant theoretical and empirical information that supports the aim of the current study. The review of the literature will include four topic areas. First, parenting stress will be discussed in order to highlight the role that everyday stress plays on parental perceptions. Second, the impact of child behavior on parenting stress will be reviewed. Third, parent/child problems and its relation to parenting stress will be discussed. Finally, developmental assessments and how they can impact the levels of parental stress will be discussed.

\section{Parenting Stress and Distress}

Some of the problems parents are faced with are everyday life occurrences. These events, which can increase parent stress, also seem to be linked to the development of behavior problems in children (Menaghan, 1999). Most scholars define a causal pathway whereby the life stress a parent experiences results in less effective parenting behavior. For example, Christophersen and Mortweet (2003) state that parenting styles are negatively influenced by the amount of stress the parent is experiencing. Poor parenting 
behavior leads to poorer child adjustment. Poorer child adjustment, in turn, makes parenting a more aversive and less rewarding experience for the parent, thus continuing to add to parent distress.

According to Cogner, McCarty, Yang, Lahey, \& Kropp (1984) parental stress has been linked to the negative perception of children and their behaviors. A parent who is under a great deal of stress will not be as likely to have the patience nor may the ability to truly see what actually be happening with their child. Stress can reduce the quality of parenting provided simply because of the pressure that a parent may be experiencing. When a parent is experiencing a great deal of stress, their abilities to rationally understand sequences of events and logically use problem-solving skills are diminished. (Heller, \& Baker, 2000).

Although most of the literature today suggests that positively impacting parents also positively impacts a child's developmental process, some scholars disagree. Some studies seem to indicate that positive parental response impacts the developmental process only in specific circumstances. For example, Erickson Warfield and colleagues concluded that early intervention for positive parental functioning has greater positive impact on mothers of children with no motor impairments versus mothers of children with impairments (EricksonWarfield, Hauser-Cram, Wyngaarden Krauss, Shonkoff, \& Upshur, 2000). These scholars argued that parental stress can be reduced, but only when developmental disorders are not present. In contrast, Summers (2002) indicated that there is a greater need for early intervention for families with children who have been diagnosed with some type of developmental disability. The fact that there exists some 
inconsistency in conclusions that scholars reach about whether or not parenting stress can be reduced indicates the need for further research.

\section{Child Problems and Parenting Stress}

A child's development is influenced by distal factors such as their environment and culture, but most proximally, and most strongly, by their parent's relationship with them. Many studies have indicated that a good relationship between parents and children is critical for the positive development of that child (Cox \& Harter, 2003). Positive parenting styles promotes children to have a positive outlook in life rather than a negative one (Heller, T.L., \& Baker, B.L., 2000). Additionally, children who have been exposed early in life to positive parenting techniques later have better social skills (Smith, Landry, \& Swank, 2000). Thus, a child who is exposed to proper parental communication styles and behavior will be more likely to behave accordingly versus a child who has been exposed to inappropriate parental behavior. Children model behavior (Wicks-Nelson \& Israel, 1997), but most parents do not realize how much their own behavior is related to their child's behavior.

Children will misbehave, and how parents perceive this type of behavior and respond to it will impact the child's overall development. Parents become stressed when their child exhibits behavior that may be age- appropriate, but does not match their expectations. When a parent has expectations for a child's behavior that are not met, a cycle of escalated frustration and negativity can begin. Unfortunately, this frustration can lead to additional parenting stress and other kinds of stress such as marital stress, personal discouragement, and an anxious "problem focus" on the child (Montgomery, DeBell, \& Wilkins, 1998). Parental distress leads to negativity in the family, which leads 
to stress and many other stress-related emotions (Cumberland-Li, Eisenberg, Champion, Gershoff, \& Fabes, 2003). Child behaviors have been found to be directly linked to parent's negative perception of their child (Pinderhughes, Dodge, Bates, Pettit \& Zelli, 2000). Parents who are having difficulty with their children in addition to experiencing high levels of stress will begin to feel a sense of hopelessness and may see their stress as a direct result of their child's behavior, which may or may not be true.

The developmental process of a child is complex and multi-dimensional. Social, emotional, cognitive, and physical development are very much influenced by parent child interaction. Both children and parents need the proper tools in order to achieve a smooth and healthy developmental process. Early interventions have positive results for both parents and children and their relationship (EricksonWarfield, Hauser-Cram, Wyngaarden Krauss, Shonkoff, \& Upshur, 2000). Parental awareness is an important factor that assists the child through the developmental process. Parental acceptance is a known factor in the positive development of the child's own perceptions of acceptance and psychological adjustment (Turner, Sarason, \& Sarason, 2001). A child who feels that they are accepted will react more positively in the face of adversity.

Parent/Child Dysfunction and Parenting Stress

In order to achieve developmental stability, a positive parent-child relationship must exist (Cox \& Harter, 2003). Positive parental perception of children and family life influences the well being of all involved (Erickson Warfield et al., 2000).

Both negative and positive reactions and behaviors can be perceived by all of those that are exposed to it. A child who is reared in a negative family environment will be more likely to demonstrate externalizing behavior problems (Thompson, Hollis, \& 
Richards, 2003). Low levels of negative emotions in parents were found to be directly associated with positive developmental outcomes in children (Cumberland-Li et al., 2003). A study conducted by Heller and Baker (2000) found that maternal negativity in parent-child interactions is positively related to both the existence and persistence of externalizing behavior in children. Similar studies have shown that maternal authoritarian attitudes may be significant in the development of conduct problems in children (Thompson et al., 2003).

Child and parent behaviors alike impact everyone in a family unit (Suarez \& Baker, 1997). Families, as any other unit of people, impact each other with their behavior. If a parent is on edge as a result of external factors combined with normal everyday stressors, this will likely impact the way a child will respond to them (Pinderhughes, Dodge, Bates, Pettit \& Zelli, 2000). In turn, parents will perceive their child as being more problematic. A parent that believes that their behaviors cannot either positively or negatively impact the outcome of their child will likely be more punitive with their children (Pinderhughes, Dodge, Bates, Pettit \& Zelli, 2000). This type of negative perception will impact the overall outcome of the child as well as the family itself. Also, when parents are experiencing higher levels of parental stress, they are more likely to be more punitive with their punishment of their children than in less stressful circumstances (Pinderhughes, Dodge, Bates, Pettit \& Zelli, 2000).

When parents seek expert opinion about their adolescent or child, their anxiety about their child is often at an all-time high, and their confidence in their own ability to parent effectively may be at an all-time low. Stressful life events for the parent or a crisis event at the child's school can precipitate a rise in parents' anxiety. According to family 
systems theorists, when parents become anxious about their child, they typically adopt more rigid beliefs and behaviors, thus exacerbating problems even further (Kerr \& Bowen, 1988). Additionally, parents may respond to increased parenting stress by disengaging from the child, or by alternating chaotically between attempting to control the child and abandoning all efforts to influence the child's behavior.

\section{Developmental Assessments and Parenting Stress}

Developmental assessments focus on the individual's development throughout the maturation process (Bradley, 1998). This type of assessment uses broad rather than specific factors that assist the professional in identifying any maladjustment of the individual during the stages of development (Vernon, 1993). According to Bradley (1998), the term developmental assessment is derived from the procedure of the assessment that uses various screening measures and instruments to look at the individual's progress through the developmental stages. In turn, the aim of a developmental assessment is to establish where the child or adolescent is developmentally. Developmental assessments are predominantly based on developmental psychology and assumptions that when intervening with a child, it is crucial to understand the importance of social, emotional, and cognitive factors have on a child's adaptation to the environment (Davis Kirsch, 2001).

As noted in Chapter 1, developmental assessments can assist professionals in determining a child's developmental progress and a parent's interaction with his/her child. During assessment feedback sessions, parents can obtain personalized information on what problems may or may not be present for their child, and brief advice about what needs to be done in order to improve their child's development. Recently, Dunsmore and 
Karn (2001) demonstrated that a mother's perception of her child's developmental process was related to her responsiveness to her child.

Some have claimed that enhancing parenting skills through providing information about child development can eventually lead to improved outcomes for children (e.g., Ginsberg, 1997). Additionally, child health specialists have advocated using assessment opportunities in clinical settings to provide parents with information about what they can do to enhance their children's growth, development, and functioning (Nelson, Wissow, \& Cheng, 2003). Indeed, many parents report that they learn new ideas, feel a sense of relief, and realize that they are not alone with their questions after they discuss their child's development with a professional (National Center for Infants, Toddlers, \& Families, 1997). Thus, developmental assessment interventions may be an efficient and practical way to reduce parent stress, and thereby enhance parent functioning. Research on Parental Stress using the Parenting Stress Inventory

The Parenting Stress Inventory (PSI) has been developed and used extensively to study parent stress and parent-child functioning (Abidin, 1990). For example, previous research done using the PSI as a measure for parental stress has indicated that mothers who report high levels of stress also report having more negative attitudes toward their children's behavior (Bigras, LaFreniere, \& Dumas, 1996). According to these results, high levels of stress negatively impacts parental perception of their child's behavior. According to Anastopoulos, Guevremont, Shelton, \& Dupaul (1992) parental stress is impacted by how parents perceive their child's behavior, as well as the ambiguity of why a negative behavior may be occurring. 
Parents who are experiencing a high level of stress are more likely to be more controlling in their parenting techniques along with having a more negative outlook on their parenting (Bigras, LaFreniere, \& Dumas, 1996). Children's behaviors, especially difficult or negative ones, clearly impact parental stress (Barkley \& Cunningham, 1979). A parent who is experiencing high levels of stress will more likely have a more negative perception of the source of their stress, which in most cases impacts their child's behavior and their response to it (Bigras, LaFreniere, \& Dumas, 1996).

The PSI helps to distinguish where parental stress is most acute, in relation to themselves as well as their child (Bigras, LaFreniere, \& Dumas, 1996). According to Abidin (1990), the PSI was designed with the belief that stressors in general are multidimensional in terms of where they are derived from and what they are. The parent and child relationship is highly influenced by how much stress the parent may be experiencing (Anastopoulos, Guevremont, Shelton, \& Dupaul, 1992). According to Bigras, LaFreniere, \& Dumas (1996) it is important to note that a parent who is experiencing high levels of stress as a result of parenting will not have the ability to perceive their child positively, especially when the child is being viewed as the primary source of stress for this parent.

Recent studies have also found that the Parenting Stress Index-Short Form, derived from the original Parenting Stress Index full-length test (Abidin, 1990), is a practical tool in the study of parenting stress. The PSI-SF was developed as a brief measure of parental stress that could be administered in under 10 minutes (Abidin, 1990). According to previous research that was conducted by Castaldi (1990), factor-analysis done of the full length version of the PSI and suggested that a three factor solution was 
the best way that this data could be described. As a result, the PSI-SF is generally used to examine three factors, which are each represented by a PSI-SF subscale score: Parental Distress, Parent-Child Dysfunctional Interaction, and Difficult Child.

The first subscale of the PSI-SF, known as Parental Distress (PD), establishes the level of distress a parent is experiencing as a result of their parental role that is derived from personal factors related directly to parenting (Abidin, 1990). Some of the personal factors that impact this subscale are parents negative perception of their parenting competence, stresses associated with restrictions due to the other life roles that the parent has, conflict with the child's other parent, lack of social support, as well as the presence of depression (Abidin, 1990). It is likely that parents that score high levels of stress that is derived from this scale are experiencing personal adjustment issues that have only partial implications to their parental roles. As a result, experts who use the PSI in clinical setting assert that parents scoring high on this domain should be referred for professional services that focus on their personal adjustment.

The Parent-Child Dysfunctional Interaction (P-CDI) subscale focuses on the parents' perception that their child may not be meeting their expectations, and that their interactions with their child are not reinforcing their parenting (Abidin, 1990). For the most part, the parent who is experiencing high levels of stress associated with this subscale is likely to feel that the primary source of their stress is their child, and as a result, perceive that child negatively. A high score on this subscale suggests that the parent-child bond is currently threatened, or worse, it has never been fully established (Abidin, 1990). Rapid intervention in this case is necessary in order to prevent potential incidences of child abuse, neglect, or rejection as a result of the parents' perception of 
their child. Conversely, if the parent receives a low score on this subscale it suggests that parental control is intact, and overall, the parent seems to be managing their child's difficult behavior or their difficult personal characteristics adequately (Abidin, 1990).

The final subscale, known as the Difficult Child (DF) subscale, measures parent's perceptions of the child's behavioral characteristics that make them more difficult to manage (Abidin, 1990). Parents' perceptions of the difficultness of their child are usually derived from the child's temperament, but child difficultness can also include learned patterns of defiant, noncompliant, or demanding behavior (Abidin, 1990). When a parent scores high on the DF subscale it suggests that the child is experiencing significant problems with self-regulation, which can make parenting quite stressful (Abidin, 1990). Experts agree that a parent who scores high on this subscale should receive recommendations to seek assistance with behavioral management techniques that can assist both the child and the parent in regulating this problem behavior.

\section{Summary}

In summary, we can draw from previous research that parental perception will influence parental stress. A parent who feels that there is a problem with his/her child will more likely experience some level of ambiguity and in result their level of stress will increase. Furthermore, a parent that feels that there is no hope will perceive their child's behavior negatively and will increase parental stress. Providing parents with information regarding their child's development and ways in which certain behaviors can be reduced, will likely decrease the level of stress a parent experiences in respect to their child's behavior problems and other forms of stress. 
Research Hypothesis

Do developmental assessments impact parental stress? To address this research question, the following hypotheses will be assessed.

Hypothesis 1: Parent stress will be reduced following a developmental assessment intervention, as manifested by lower pre- to post-test scores on the Parent Distress subscale of the Parenting Stress Inventory-Short Form (PSI-SF).

Hypothesis 2: Parents' estimations of their child's problems will be reduced following a developmental assessment intervention, as manifested by lower pre- to post-test scores on the Difficult Child subscale of the PSI-SF.

Hypothesis 3: Parent-child dysfunction will be reduced following a developmental assessment intervention, as manifested by lower pre- to post-test scores on the Parent-Child Dysfunctional Interaction subscale of the PSI-SF.

Hypothesis 4: Total parenting stress will be reduced following a developmental assessment intervention, as manifested by lower pre- to post-test scores on the Total Parent Stress scale of the PSI-SF. 


\section{CHAPTER III}

\section{METHODOLOGY}

\section{Participants}

The participants were recruited from a Southeast Florida community and were self referred to the Youth and Family Development Program at Florida International University. The sample included a total of 25 parent/child dyads with children between 4 to12 years of age who sought developmental assessments at the Youth and Family Development program at Florida International University. Child participants included 3 4-year-olds (12\%), 3 5-year-olds (12\%), 2 6-year-old (8\%), 3 7-year-olds (12\%), 18 year-old (4\%), 6 9-year-olds (24\%), 10-year-olds (16\%), 2 11-year olds (8\%), and 112 year-old (4\%); the mean age children was 7.8 years. Sixteen of the children were males (64\%) and 9 were females (36\%). Of the 25 families, 20 (80\%) were Hispanic, four (16\%) were non-Hispanic white, and one (4\%) was Jamaican.

Parent participants included 23 (92\%) mothers, with a mean age of 33.3, and 2 (8\%) fathers, with a mean age of 38. Marital status included the following: 19 participants (76\%) were married, 5 participants (20\%) were divorced, and 1 participant was separated (4\%).

\section{Procedures}

Volunteer participants were recruited from parents who called the Youth and Family Development Program (YFDP) laboratory. Parents who called the YFDP were from neighboring communities in Southeast Florida. At the time of the initial contact the 
participants were given the option to participate in the research study conducted by the Youth and Family Development Program at Florida International University, and informed that if they were willing to participate in this study, the fee for a developmental assessment would be reduced. Participants were told that the study would require them to complete a pre- and post-assessment over the telephone, and three in-office sessions including two sessions to complete the assessments and one session for feedback on the results. The participants were informed that they would be completing a series of assessments that would assist the interventionists in determining whether a) there were any developmental or mental health issues that needed to be addressed, b) the quality of parent and child interactions, and c) the level of parental stress. Parents who agreed to participate in the study completed the pre-test (PSI-SF) over the phone and were scheduled for their first in office visit within one to two weeks of their initial contact. The office visits were dependent on parent availability and scheduling.

During the first in-office session (Week 1), parents signed a written consent to participate in this study, authorized recording, and authorized the exchange information with teachers or physicians (if requested). Next, the parent and child participated in a Play Task (requiring about 20 minutes) together. Once the play task was completed, the parent and child were taken into separate rooms. The parent was asked to begin completing the self report measures, which included Demographics, the PSI regular form (Abidin, 1990) and an assessments of child behavior, while the child remained in the playroom to begin completing the measures appropriate to their age level. At the end of the one-hour session, assessments were concluded and the participants were dismissed and scheduled for the next session (Week 2). During the second session, the parent and 
child were placed into separate rooms where each completed the remaining assessments. Children completed age-appropriate developmental assessments mental health screening instruments.

Once the participants completed all of the measures they were excused and the parent was asked to return alone in two weeks (Week 4) for a feedback session on the results. (For some parents, this period of time was a few weeks longer due to the parent's availability and scheduling difficulties.) During the feedback session, the parent was given written and oral feedback on the results of the assessments pertaining to their child and the parent-child relationship. The assessment results were tied to age-appropriate expectations for the child. The strengths and weaknesses were highlighted, and recommendations addressing problematic areas identified in the assessment by the parent were made. If indicated by the PSI profile, parents were advised to seek treatment for themselves (e.g., if the parent distress score was in the clinical range), additional assessment for their child (e.g., if the child problems score and scores on other clinical measures given suggested the potential of a psychiatric diagnosis), or filial/family therapy (e.g., if the parent/child dysfunctional interaction score was in the clinical range) as a part of the feedback given. One week after the feedback session, every participant was sent a letter of acknowledgement which also reminded them of the follow-up phone session in one month. During the follow-up phone call, the parent was asked to complete over the phone another Parenting Stress Index-Short Form. The post-test required 12-15 minutes in order to complete. 
As noted above, parent and child participants were given a series of established self-report measurements, interview assessments, and a dyadic observational assessment. Measures used to assess the hypotheses for this study are detailed below.

\section{Demographic Questionnaire}

This instrument gathered information such as age, gender, ethnicity, language, parents' education, and income. For clinical purposes, it also collected information about past medical conditions or psychological conditions for parent and child.

\section{The Parenting Stress Index}

The Parenting Stress Index (Abidin, 1990) measured the relative magnitude of stress in the parent-child system, as well as issues regarding child behavior problems and parent characteristics. The PSI is a self-report measure with 120 items, to which parents respond with a 5-point Likert scale ranging from 1 (strongly agree) to 5 (strongly disagree) (e.g., "It is hard to find a place in our home where I can go to be by myself" and "Having a child has caused changes in the way I sleep"). Some items in the PSI require a response that is different than "1 (strongly agree)," in which case a choice of answers are provided to choose from (eg. "For the next statement choose your responses from the following choices 1-5 below"). These items yield scores in Parent Domain Stress and Child Domain Stress, which can be totaled to yield a Total Parenting Stress score. High levels of parental stress are indicated by high scores on each subscale and for the overall test score. The PSI also contains a Life Stress subscale that is optional, and the responses are either "yes" or "no", with higher scores indicating that parents have 
recently experienced greater numbers of stressful life events (e.g., moves, divorce, and death in the family).

The test-retest reliability reported by Abidin (1990) indicates coefficients for the PSI scales: parent domain, .91; child domain, .63; and total stress, .96. Previous research indicated test-retest reliability coefficients for the PSI scales: parent domain, .70; child domain, .55; and total stress, .65 (Hamilton, 1980). The alpha reliability coefficients for the PSI are reported by Abidin (1990) for the PSI scales are parent domain, .93; child domain, .90; and total stress, .95. Previous research indicates internal consistency for the PSI scales to range between .70 to .84 for the parent domain; .70 to .83 for the child domain; and .90 or higher for total stress.

In this study, a computer scoring program provided by the Psychological Assessment Resources, Incorporated was used to calculate parents' scores using agenormed scoring keys. Parents received feedback based on their scores on all the PSI scales and subscales; however, for the purposes of this study, only the Total Parenting Stress score was used.

\section{Parenting Stress Index-Short Form}

This assessment was used as the pre and post-test. It consists of 36 self-report items that on a 5-point Likert scale ranging from 1 (strongly agree) to 5 (strongly disagree). There are some questions that require a different response from " 1 " (strongly agree) at which the question will prompt for a specific answer to choose from a list that is provided (eg. "For the next statement, choose the response from the following choices "1-5" provided below". Like the PSI full version, the PSI-SF is designed to measure the 
level of stress in the parent-child system. The PSI-SF is divided into three subscales that measure Parental Distress, Difficult Child, and Parent-Child Dysfunctional Interaction. Adequate reliability and validity for the PSI-SF has been found in numerous studies done on family functioning (Lloyd and Abidin, 1985). The test-retest reliability coefficients for the PSI-SF subscales, according to Abidin (1990) include: parental distress, .85; parentchild dysfunctional interaction, .68; difficult child, .78; and total stress, .84 . The alpha reliability coefficients for the PSI-SF subscales reported by Abidin (1990) include: parental distress, .87; parent-child dysfunctional interaction, .80; difficult child, .78; and total stress, .91 .

In this study, a computer scoring program provided by the Psychological Assessment Resources, Incorporated was used to calculate parents' pre- and post-test scores on Parental Distress, Difficult Child, and Parent-Child Dysfunctional Interaction, and Total Parenting Stress using age-normed scoring keys. 


\section{CHAPTER IV}

\section{RESULTS}

In this section, the steps taken prior to testing the hypotheses will be presented

first. Results of the tests of hypotheses will be presented next. Finally, a post-hoc analysis was done to further explore the results, will be reviewed.

\section{Preliminary Analyses}

First, parent profiles were inspected for their validity. The PSI scoring program provides a "defensive responding" score based on the parents' pattern of responses, in order to identify invalid protocols. One case was identified as invalid as the participant scored at the $99^{\text {th }}$ percentile of defensive responding at both pre- and post-test. This case was eliminated from the subsequent analyses. Of the remaining cases, $19(76 \%)$ scored in the clinical range on one or more scale of the PSI at pretest. As shown in Table 1, only 3 of these cases, or $12 \%$ of the sample, scored in the clinical range on one or more scales at the post-test.

Second, the PSI-SF subscale inter-correlations were assessed, at both pre-test and post-test, using Pearson product-moment correlational statistics (two-tailed). As shown in Table 2, at pre-test, parent-child dysfunction and parent distress were significantly correlated, $r=.49, p<.01$. Parent-child dysfunction was also strongly correlated with total parenting stress, $r=.82, p<.001$. Parent distress was correlated with total parenting stress, $r=.72, p<.001$, as were parents' scores on the difficult child scale, $r=.46, p<$ .05. At post-test, the pattern of inter-correlations was similar: Parent-child dysfunction was positively correlated with parent distress, $r=.62, p<.01$ and total parenting stress, $r$ $=.71, p<.001$. Parents distress was also positively correlated with scores on the difficult 
child scale, $r=.47, p<.05$, and with total parenting stress, $r=.79, p<.001$.

Additionally, total parenting stress was significantly correlated with scores on the difficult child scale, $r=.69, p<.001$. At both times of assessment, parents' scores on the difficult child scale were not correlated with their scores on the parent-child dysfunction scale.

The associations between PSI pre-test scores and post-test scores were also analyzed using Pearson product-moment correlational statistics (two-tailed). As shown in Table 3, scores at pre-test and at post-test were largely uncorrelated, with a few exceptions. Parent-child dysfunction at pretest was correlated with parent-child dysfunction at post-test, $r=.58, p<.01$; parent distress was also moderately correlated at pre- and post-test, $r=.48, p<.05$. Additionally, parent distress at pre-test was moderately correlated with total parenting stress at post-test, $r=.42, p<.05$. Primary Analysis

To test the hypothesis for this study, a series of repeated measures analyses of variance (RANOVA) were performed to test for differences in parental stress as a function of time (before and after receiving a developmental assessment). The dependent variables included the pre-developmental assessment and post-developmental assessment Parent Stress Inventory percentile scores on Parental Distress, Difficult Child, ParentChild Dysfunctional Interaction, and the Total Stress Score of the Parenting Stress Inventory-Short Form (PSI-SF).

Results indicated that parent stress was significantly lower at post-developmental assessment than at pre-developmental assessment on the Parent Distress subscale of the $(M=54.56$ vs. $M=19.04), F(1,24)=51.50, \mathrm{p}<.001, \eta_{\mathrm{p}}{ }^{2}=.68 ;$ the Difficult Child 
subscale $(M=83.92$ vs. $M=39.28), F(1,24)=70.72, \mathrm{p}<.001, \eta_{\mathrm{p}}{ }^{2}=.75 ;$ the Parent-Child Dysfunctional Interaction subscale $(M=77.20$ vs. $M=51.76), F(1,24)=41.07, \mathrm{p}<.001, \eta_{\mathrm{p}}{ }^{2}$ $=.63$; and on the Total Parenting Stress Score $(M=80.04$ vs. $M=29.96), F(1,24)=$ 83.24, $\mathrm{p}<.001, \eta_{\mathrm{p}}{ }^{2}=.78$. Thus, while all hypothesis tests with respect to the domains of parenting distress were supported, the effect size was largest for the parent distress and smallest for parent-child dysfunctional interaction.

Follow-up Analyses

As an exploratory analysis, the pre- and post-developmental assessment scores were also compared with the total stress score from the PSI (regular version), obtained during parents' first visit to the Youth and Family Development Program. The RANOVA comparing scores across both measures was significant, $F(1,23)=95.98, p<$ .001 , partial ETA squared $=.80$. Post hoc follow-up tests using Bonferroni correction showed that the total parenting stress percentile score was significantly lower when parents completed the PSI during their first visit than it was when they completed the PSI-SF during the first phone contact $(p<.001)$, and significantly lower during the follow-up phone contact that during the first visit $(p=.002)$. 


\section{CHAPTER V}

\section{DISCUSSION}

The purpose of this study was to compare levels of parental stress before and after a developmental assessment intervention took place. Specifically, because of previous assertions that had been made about the potential for personalized information about child development to positively impact parents (National Center for Infants, Toddlers, \& Families, 1997; Simpson, Korolof, Friesen, \& Gac, 1999), it was predicted that parents would report lower levels of total parenting stress at the follow-up assessment four weeks after the developmental assessment than at the pre-test assessment taking place at first phone contact with the Youth and Family Development Program. The results of this study confirmed this prediction, as total parenting stress scores were significantly lower after the developmental assessment.

Specific hypotheses were also confirmed for each of three subscales of the PSISF. Parent Distress decreased significantly from pretest to post-test, suggesting that the developmental assessment intervention, which involved providing parents with personalized information about their child's development, psychological adjustment, and family interaction patterns, did reduce parents' distress. This result is consistent with....

Scores on the Difficult Child scale also decreased significantly from pre-test to post-test, suggesting that the developmental assessment intervention reduced the parents' negative evaluations of their child's behavior. This result is consistent with the notion that providing information about child development that helps parents decrease unrealistic expectations for their child and increase realistic ones will help parents expand the attributions they make for their child's behavior beyond negative, personal ones. 
Finally, scores on the Parent-Child Dysfunctional Interaction decreased

significantly from pre-test to post test, suggesting that the developmental assessment intervention reduced the occurrence of certain types of interactions that the PSI-SF identifies as dysfunctional. During the developmental assessment intervention, family functioning was assessed and parents received feedback about their family cohesion and the strength of parent-child bond, evidence of negative impact on the child from family conflict, and their balance of adaptability/flexibility versus routines and structure. This result suggests that the developmental assessment intervention may improve these aspects of parent-child functioning, thus reducing this type of parent stress.

It is also noteworthy that certain types of parenting stress appeared to be more amenable to change than others. While all hypothesis tests with respect to the domains of parenting distress were supported, the effect size was largest for the parent distress and smallest for parent-child dysfunctional interaction. This pattern of results can also be seen in the correlations of the PSI pre-test and post-test scores, as parent-child dysfunction at pre-test was significantly correlated with parent-child dysfunction at posttest. Taken together, these results imply that parent-child dysfunction might be impacted less by a developmental assessment intervention than would parent distress or parent perceptions of child difficulties; a conclusion that would be consistent with the notion that developmental assessment interventions give parents realistic expectations for child behavior and reduce a "problem focus" on the child (Montgomery, DeBell, \& Wilkins, 1998). Changing parent-child interaction patterns would likely require more intensive and focused intervention (e.g., filial therapy; Kale \& Landreth, 1999). 
While the tests of the hypotheses did reveal significant reductions in parent distress between the two times of assessment, these changes may be due to other factors rather than the developmental assessment intervention itself. There are several alternative explanations that cannot be ruled out, due to limitations in the design of this exploratory study. The first and most probable confound would the phenomenon of "regression toward the mean", which is the common finding that upon retesting, extreme scores tend to migrate toward the mean as a function of chance alone. In the case of this study, parents making contact with the Youth and Family Development Program were those who, due to intended selection effects, had more extreme scores in the direction of problematic parent stress. According to the "regression" phenomenon, parents' scores would decrease simply due to chance at a second time of measurement, although the PSISF's test-retest reliability performance in previous studies suggests that this would be a limited effect.

The significant passage of time between pre-test and post-test (in most cases, approximately 10 weeks) also might have been associated with other factors causing change (similar to the "improvements" often seen in participants assigned to wait lists in controlled clinical studies). In order to explore this possibility, the total parenting stress scores obtained from the PSI regular version were obtained in a paper-and-pencil survey assessment during parents' first session at the Youth and Family Development Program. Indeed, significant improvements were seen between the pre-test and the first in-clinic session (and before the developmental session feedback took place), suggesting that the passage of time might indeed be a causal factor. However, the phenomenon of symptom 
reduction even during the first office visit is often observed in clinical practice, and may be attributed to "expectant faith" generated by the expectancy for relief that comes from entering into a relationship with another person who is perceived as expert, stable, and competent to help (Frank, 1982; Scovern, 2005). Most important for this study, the parenting stress did not level off or increase following the significant reductions between pre-test and first visit; rather, they continued to decrease significantly.

\section{Limitations}

Several other limitations to this study must be considered. First, this study used a relatively small sample. Typically, a small sample decreases the power to detect significant associations. However, in this study, the differences between parenting stress at the different assessment points were quite robust and detected even with a small sample. Nevertheless, conclusions about the generalizabilty of this study to other populations and other clinical settings must be made carefully.

Second, the evaluator who administered the pre- and post-assessments also, in many instances, delivered the developmental assessment intervention. Thus, the rapport established with her may have influenced the assessment of parenting stress, particularly, the post-test assessment, which occurred after many occasions of contact.

Third, the sample in this study was almost entirely composed of Hispanic families, and the parent stress in Hispanic families has been studied very little. It may be that stress in such families is impacted by intervention in a different way, or to a different extent, than other families. (On the other hand, it may not, but this question has not been empirically evaluated so caution is merited until conclusions can be drawn.) 
Finally, although the results of this study suggest that delivering a developmental assessment intervention can have a positive impact on parents' stress, including their own distress, parent-child dysfunction, and child adjustment difficulties, it was assessed only in a university-based laboratory setting. Before concluding that developmental assessment interventions would be effective in schools or other community-based practice settings, further study is needed.

\section{Contribution to Knowledge}

Despite these limitations, this study begins to address the need for intervention programs that are designed to alleviate some of the principal concerns a parent may have with respect to their child's behavior. Interventions that teach parents age-appropriate behaviors for children can alleviate the pressure many parents place on themselves and their children. Parents who contact professionals due to concerns about their child are typically experiencing stress that is in acute ranges, as was the case for $76 \%$ of the participants in this sample. However, far fewer parents (12\%) had scores that placed them the range of clinical concern following the developmental assessment intervention. Thus, a developmental feedback intervention appears to be not only feasible to provide with limited resources, it appears to be effective in reducing parent stress. Additionally, it is an intervention that parents seem to find palatable and possible to complete. Because of its promise for efficiently reducing many aspects of parent stress and distress, additional controlled studies the effectiveness of developmental feedback interventions for reducing parent stress and parent-child problems is merited. 
Abidin, R. R. (1990). Parenting Stress Index Manual. Charlottesville, VA: Pediatric Psychology Press.

Achenbach, T. \& Edelbrock, C. (1987). Child Behavior Checklist. Burlington, VT: University of Vermont, Department of Psychiatry.

Anastopoulos, A. D., Guevremont, D. C., Shelton, T. L., \& DuPaul, G. J. (1992).

Parenting stress among families of children with attention deficit hyperactivity disorder. Journal of Abnormal Child Psychology, 20, 503-520.

Barkley, R. A., \& Cunningham, C. E. (1979). The effects of Ritalin on the mother-child interactions of hyperactive children. The Archives of General Psychiatry, 36, 201208.

Bradley, R. H. (1998). In defense of parental investment. Journal of Marriage and the Family, 60, 791-795.

Bigras, M., LaFreniere, P. J., \& Dumas, J. E. (1996). Discriminant validity of the parent and child scales of the parenting stress index. Early Education and Development, 7, 167-178.

Carr, E.G., Dunlap, G., Horner, R.H., Koegel, R.L., Turnbull, A.P., Sailor, W., Anderson, J.L. Albin, R.W., Koegel, L.K., \& Fox, L. (2002). Positive behavior support: Evolution of applied science. Journal of Positive Behavior Interventions, 4, 4-16.

Castaldi, J. (1990). Affective and cognitive patterns in the mother-child relationship during the second year of life. Unpublished doctoral dissertation. University of Virginia, Charlottesville.

Christophersen, E. R., \& Mortweet, S. L. (2003). Parenting That Works: Building Skills that Last a Lifetime. Washington, D.C.: American Psychological Association.

Cogner, R., McCarty, J., Yang, R., Lahey, B., \& Kropp, J. (1984). Perception of child, child-rearing values, and emotional distress as mediating links between environmental stressors and observed maternal behavior. Child Development, 54, 2234-2247.

Cox, M.J. \& Harter, K.S.M. (2003). Well-being: Positive development accross the life course. Crosscurrents in contemporary psychology. In M.H. Borenstein \& L. Davidson (Ed.), Parent-child relations. (pp. 191-204). New Jersey: Lawrence Erlbaum Associates. 
Cumberland-Li, A., Eisenberg, N., Champion, C., Gershoff, E. \& Fabes, R.A. (2003). The relation of parental emotionality and related dispositional traits to parental expression of emotion and children's social functioning. Motivation \& Emotion, $27,27-56$.

Davis Kirsch, S. (2001). Congruence of self, parent, teacher and peer perceptions of social competence in the early school age child. Dissertation Abstracts International: Section B: The Sciences \& Engineering 61(11-B), 5796.

Dunsmore, J.C. \& Karn, M.A. (2000). Mothers' beliefs about feelings and children's emotional understanding. Early Education \& Development, 12, 117-138.

Erickson Warfield, M., Hauser-Cram, P., Wyngaarden Krauss, M., Shonkoff, J.P., \& Upshur, C.C. (2000). The effect of early intervention services on maternal well being. Early Education \&Development, 11, 499-517.

Furman, W., \& Adler, T. (1982). The Friendship Questionnaire. Denver: University of Denver.

Frank, J. (1982). Biofeedback and the placebo effect. Biofeedback and Self Regulation, $7,449-460$.

Gestwicki, C. 2000. Home, school, and community relations: A guide to working with families ( $4^{\text {th }}$ Edition). Albany, NY: Delmar.

Ginsberg, B.G. (1997). Relationship Enhancement Family Therapy. NY: John Wiley \& Sons, Inc.

Gorzka, P. A. (1999). Homeless parents: Parenting education to prevent abusive behaviors. Journal of Child and Adolescent Psychiatric Nursing, 12(3), 101-109.

Hamilton, E.B. (1980). The relationship of maternal patterns of stress in families with trainable mentally retarded children. Unpublished doctoral dissertation, University of Virginia, Charlottesville.

Heller, T.L., \& Baker, B.L. (2000). Maternal negativity in children's externalizing behavior. Early Education \& Development, 11, 483-498.

Kale, A. L., \& Landreth, G. L. (1999). Filial therapy with parents of children experiencing learning difficulties. International Journal of Play Therapy, 8, 3556.

Kerr, M. E., \& Bowen, M. (1988). Family evaluation: An approach based on Bowen theory. New York: Norton. 
Lloyd, B. H., \& Abidin, R. R. (1985). Revision of the Parenting Stress Index. Journal of Pediatric Psychology, 22, 43-54.

Menaghan, E. (1999). Social stressors in childhood and adolescence. NY: Cambridge University Press.

McConaughy, S.H., \& Achenbach, T.M., (2001). Manual for the Semistructured Clinical Interview for Children and Adolescents ( $2^{\text {nd }}$ edition). VT: University of Vermont, Research Center for Children, Youth \& Families.

Montgomery, J. M., DeBell, C. \& Wilkins, J, (1998). Calming anxiety: developmental interventions for multigenerational parent-child therapy. The Family Journal: Counseling and Therapy for Couples and Families, 6, 87-93.

Moos, R. H. \& Moos, B. S. (1986). Family Environment Scale Manual (2 $2^{\text {nd }}$ ed.) Palo Alto, CA: Consulting Psychologists Press.

National Center for Infants, Toddlers, and Families (1997). New Visions: A Parent's Guide to Understanding Developmental Assessment.

National Institute on Drug Abuse Clinical Trials Network (n.d.). What are clinical trials? Retrieved June 23, 2005 from http://www.nida.nih.gov/CTN/brochures/br_clinical_trial.html

Nelson, C.S., Wissow, L.S., \& Cheng T.L. (2003). Effectiveness of anticipatory guidance: recent developments. Current Opinions in Pediatrics, 15, 630-635.

Olson, D.H., Portner, J., \& Lavee, Y. (1985). Family Adaptability and Cohesion Evaluation Scales. MN: University of Minnesota.

Piaget, J. (1967). Six psychological studies. New York: Vintage Books.

Pinderhughes, E. E., Dodge, K. A., Bates, J. E., Pettit, G. S., \& Zelli, A. (2000). Discipline Responses: Influences of Parents' Socioeconomic Status, Ethnicity, Beliefs About Parenting, Stress, and Cognitive-Emotional Processes, Journal of Family Psychology, 14, 380-400.

Reitman, D., Currier, R.O., and Stickle, T.R., (2002). A critical evaluation of the Parenting Stress Index-Short Form (PSI-SF) in a head start population. Journal of Clinical Child and Adolescent Psychology, 31, 384-392.

Sabatelli, R. M., \& Waldron, R. J. (1995). Measurement issues in the assessment of experiences of parenthood. Journal of Marriage and the Family, 57, 969-980. 
Scovern, A. W. (2005). From placebo to alliance: The role of common factors in medicine. In Hubble, M. A., Duncan, B. L., \& Miller, S. D. (Eds.), The heart and soul of change: What works in therapy (pp. 259-296). Washington, D.C.: American Psychological Association.

Shepard, L., Kagan, S.L., Wurtz, E. (Eds.). (1998). Principles and recommendations for early childhood assessments. Washington, DC: National Education Goals Panel.

Simpson, J. S., Koroloff, N., Friesen, B. J., \& Gac, J. (1999). Promising practices in family-provider collaboration. Systems of care: Promising Practices in Children's mental health, 1998 Series, Volume II. Washington, D. C.: Center for Effective Collaboration and Practice, American Institutes for Research.

Smith, K.E., Landry, S.H., \& Swank, P.R. (2000). The influence of early patterns of positive parenting on children's preschool outcomes. Early Education \& Development, 11, 147-169.

Suarez, L. M., \& Baker, B. L. (1997). Child Externalizing Behavior and Parents' Stress: The Role of Social Support. Family Relations, 46, 373-381.

Summers, C.H., (2002). Social interaction over time, implications for stress responsiveness. Integrative and Comparative Biology 42, 591-599.

Thompson, A., Hollis, C., \& Richards, D. (2003). Authoritarian parenting attitudes as a risk for conduct problems: Results from a British national cohort study. European Child \& Adolescent Psychiatry, 12, 84-91.

Turner, A.P., Sarason, I.G., \& Sarason, B.R. (2001). Exploring the link between parental acceptance and young adult adjustment. Cognitive Therapy \& Research, 25, 185199.

Vernon, A. (1993). Developmental assessment and intervention with children and adolescents. Alexandria, VA: American Counseling Association.

Wicks-Nelson, R. \& Israel, A.C. (1997). Anxiety Disorders. In Janzow, P. (Eds.), Behavior Disorders of Childhood. (pp.111-141). Upper Saddle River, NJ: Prentice Hall. 
Appendix A

Table 1: Percentile Scores on PSI Subscales and Total Scale

Time of Assessment

\begin{tabular}{|c|c|c|c|c|c|c|c|c|}
\hline & 1 & 2 & 1 & 2 & 1 & 2 & 1 & 2 \\
\hline Case & $\begin{array}{l}\text { Parental } \\
\text { Distress }\end{array}$ & $\begin{array}{l}\text { Parental } \\
\text { Distress }\end{array}$ & $\begin{array}{l}\text { Dysfun- } \\
\text { ctional } \\
\text { Interac- } \\
\text { tion }\end{array}$ & $\begin{array}{l}\text { Dysfun- } \\
\text { ctional } \\
\text { Interac- } \\
\text { tion } \\
\end{array}$ & $\begin{array}{l}\text { Difficult } \\
\text { Child }\end{array}$ & $\begin{array}{l}\text { Difficult } \\
\text { Child }\end{array}$ & $\begin{array}{l}\text { Total } \\
\text { Stress }\end{array}$ & $\begin{array}{l}\text { Total } \\
\text { Stress }\end{array}$ \\
\hline 73 & 55 & 10 & 60 & 30 & $95^{*}$ & $90^{*}$ & $90^{*}$ & 45 \\
\hline 74 & 10 & 20 & 20 & 10 & 75 & 35 & 25 & 15 \\
\hline 77 & 40 & 10 & 80 & 40 & $85^{*}$ & 55 & $80^{*}$ & 20 \\
\hline 79 & 5 & 5 & 40 & 55 & 40 & 50 & 15 & 20 \\
\hline 80 & 25 & 15 & $95 *$ & 75 & $95^{*}$ & 55 & $85^{*}$ & 50 \\
\hline 81 & 60 & 5 & 80 & 30 & $90^{*}$ & 30 & $85^{*}$ & 10 \\
\hline 82 & 30 & 30 & $95 *$ & 70 & $85^{*}$ & 35 & $85^{*}$ & 45 \\
\hline 86 & 50 & 1 & 75 & 45 & 70 & 30 & 70 & 10 \\
\hline 87 & 80 & 40 & 80 & 70 & $99 *$ & $95^{*}$ & $95^{*}$ & $85^{*}$ \\
\hline 88 & 55 & 10 & 65 & 30 & 65 & 40 & 70 & 15 \\
\hline 89 & 55 & 5 & 35 & 35 & $85^{*}$ & 40 & 65 & 15 \\
\hline 90 & 40 & 15 & 65 & 55 & 60 & 40 & 60 & 30 \\
\hline 92 & 75 & 5 & $90^{*}$ & 40 & $90^{*}$ & 10 & $90^{*}$ & 5 \\
\hline 94 & $85^{*}$ & 80 & $95^{*}$ & 75 & $85^{*}$ & 40 & $90^{*}$ & 75 \\
\hline 95 & 65 & 25 & $99 *$ & $90^{*}$ & 80 & 40 & $95^{*}$ & 55 \\
\hline 96 & 40 & 10 & 80 & 60 & $90^{*}$ & 30 & $85^{*}$ & 25 \\
\hline 97 & 25 & 5 & $95^{*}$ & 60 & $85^{*}$ & 20 & $85^{*}$ & 15 \\
\hline 98 & 40 & 10 & $95^{*}$ & 45 & $95^{*}$ & 15 & $90^{*}$ & 10 \\
\hline 99 & 55 & 10 & 55 & 60 & 90 & 25 & 80 & 20 \\
\hline 100 & $95^{*}$ & 10 & 75 & 30 & 70 & 1 & $90^{*}$ & 5 \\
\hline 101 & $90^{*}$ & 25 & $99^{*}$ & 40 & $95^{*}$ & 20 & $99^{*}$ & 15 \\
\hline 102 & 40 & 10 & 60 & 40 & $85^{*}$ & 1 & 75 & 5 \\
\hline 103 & 75 & 10 & $99^{*}$ & 60 & $95^{*}$ & 25 & $99^{*}$ & 20 \\
\hline 104 & 75 & 15 & $99^{*}$ & 50 & $95^{*}$ & 65 & $99^{*}$ & 40 \\
\hline 105 & 70 & 15 & $95^{*}$ & 75 & 70 & 40 & $90^{*}$ & 45 \\
\hline
\end{tabular}

Note: ${ }^{*}$ Clinical Range $=84 \%$ or above (two standard deviations above the mean). 
Appendix B

Table 2: Inter-scale Correlations of PSI-SF scales at Pretest and at Posttest.

\begin{tabular}{lcccc} 
& Parent Distress & Difficult Child & Parent-Child & Total Parenting \\
& & & Dysfunction & Stress \\
Parent Distress & - & .22 & $.49^{* *}$ & $.72^{* * *}$ \\
Difficult Child & $.47^{*}$ & -- & .24 & $.46^{*}$ \\
Parent-Child & $.62^{* *}$ & .36 & -- & $.82^{* * *}$ \\
Dysfunction & & & & \\
Total Parenting & $.79 * * *$ & $.69^{* * *}$ & $.71^{* * *}$ & - \\
Stress & & & & \\
& & & & \\
\hline
\end{tabular}

Note: Pre-test inter-scale correlations are above the diagonal; post-test inter-scale correlations are below the diagonal. $\mathrm{N}=25$.

${ }^{*} p<.05,{ }^{* *} p<.01,{ }^{* * *} \mathrm{p}<.001$ 
Appendix C

Table 3: Correlations of PSI-SF scales at Pretest and Posttest.

Pre-Test Scores

\begin{tabular}{lcccc}
\hline & $\begin{array}{c}\text { Parent } \\
\text { Distress }\end{array}$ & $\begin{array}{c}\text { Difficult } \\
\text { Child }\end{array}$ & $\begin{array}{c}\text { Parent-Child } \\
\text { Dysfunction }\end{array}$ & $\begin{array}{c}\text { Total Parenting } \\
\text { Post-Test Scores }\end{array}$ \\
Parent Distress & $.48^{*}$ & .28 & .33 & .28 \\
Difficult Child & .13 & .21 & .02 & .08 \\
Parent-Child & .22 & .23 & $.58^{* *}$ & .39 \\
Dysfunction & & & & .37 \\
Total Parenting & $.42 *$ & .37 & & \\
Stress & & & & \\
\hline
\end{tabular}

Note: $\mathrm{N}=25 .{ }^{*} p<.05,{ }^{* *} p<.01$. 